\title{
Influence of Surface Pre-treatment of MWNTs Support on PEFC Performance
}

\author{
S. Mohanapriya ${ }^{a}$, P. Sridhar ${ }^{\mathrm{a}}$, S. Pitchumani ${ }^{\mathrm{a}}$ and A.K. Shukla ${ }^{\mathrm{b}}$ \\ ${ }^{a}$ CSIR-Central Electrochemical Research Institute-Madras Unit, Chennai-600113, India \\ ${ }^{\mathrm{b}}$ Solid State and Structural Chemistry Unit, Indian Institute of Science, Bangalore- 560012, India
}

The influence of surface characteristics of multi-walled carbon nanotubes (MWNTs) support on the catalytic performance of PEFC electrodes is investigated by using oxidized and nonoxidized MWNTs as the supports for platinum. The defect-free morphology, high electrical conductivity and favorable pore-size distribution of non-oxidized MWNTs ameliorate catalytic activity and electrochemical stability of platinum. Physico-chemical properties of oxidized and non-oxidized MWNTs and the respective catalysts are studied by BET surface-area, XRD, XPS and TEM measurements. Electrochemical stability of MWNTssupported platinum as PEFC electrodes is assessed using potential cycling and potentiostatic techniques. Owing to the higher corrosion-resistance, platinum on non-oxidized MWNTs show lower loss in electrochemical surface area (ESA) and also exhibit $22 \%$ lower corrosion current than oxidized MWNTs.

\section{Introduction}

Polymer electrolyte membrane fuel cells (PEFCs) are promising power sources for electric vehicles and portable electronic devices due to their quick start-up, fast response to varying loads and low operating-temperatures ${ }^{1}$. Nano-sized platinum $(\mathrm{Pt})$ and its alloys supported on high-surface-area carbon are common catalysts for PEFCs. Following the US DOE target to limit the Pt loading for PEFCs to $0.2 \mathrm{~g}-\mathrm{Pt} / \mathrm{kW}$ by 2015 , substantial R\&D efforts have been made to increase the mass activity of Pt. One way to increase the $\mathrm{Pt}$ mass activity for oxygen-reduction reaction (ORR) is to employ substrates that favor better Pt dispersion and ameliorate Pt utilization. In this context, multi-walled carbon nanotubes (MWNTs) have been proposed as potential support for Pt, owing to their high surface area, good electrical conductivity along with their high chemical and electrochemical stability. It is reported that Pt loading to the extent of $65 \%$ could be reduced by using MWNTs in relation to commonly used Vulcan XC-72R carbon ${ }^{2}$. However, MWNTs require suitable pre-treatment prior to $\mathrm{Pt}$ deposition that greatly influences the catalyst performance. Accordingly, MWNTs were subjected to oxidative nitric acid pre-treatment and non-oxidative hydrochloric acid pre-treatment prior to $\mathrm{Pt}$ deposition. Present study is attempt to understand the influence of surface-characteristics of MWNTs support on the performance of the PEFCs.

\section{$\underline{\text { Materials }}$}

\section{Experimental}

MWNTs ( $>95 \%$ purity) with diameter $15 \pm 5 \mathrm{~nm}$ and length of about $1 \mu \mathrm{m}$ were obtained from Nanolab Inc, USA. Chloroplatinic acid $\left(\mathrm{H}_{2} \mathrm{PtCl}_{6} \cdot \mathrm{xH}_{2} \mathrm{O}\right)$ procured from 
Alfa Aesar (UK) was used as platinum precursor. Commercially available ethylene glycol (Rankem Chemicals, India), sodium hydroxide and Ethanol (Merck, India), and Nafion (DuPont, US) were used. Toray TGP-H-120 was procured from Nikunj (India) and Vulcan XC-72R carbon from Cabot Corporation (US). De-ionized water (Millipore) of resistivity $18 \mathrm{M} \Omega \mathrm{cm}$ was used during all the experiments.

\section{$\underline{\text { Surface Oxidation of MWNTs }}$}

Oxidation of MWNTs was accomplished by refluxing $100 \mathrm{mg}$ of MWNTs with $25 \mathrm{ml}$ of $8 \mathrm{M} \mathrm{HNO}_{3}$ at $60^{\circ} \mathrm{C}$ for $6 \mathrm{~h}$. The mixture was suspended in de-ionized water and filtered using G4 crucible. Resulting nanotubes sample was washed copiously using deionized water and dried overnight in a vacuum oven at $80^{\circ} \mathrm{C}$. The sample thus prepared is referred to as oxidized MWNTs (Ox-CNT) in the following text.

\section{$\underline{\text { Treatment with } \mathrm{HCl}}$}

In order to eliminate the metallic impurities present in the as-received MWNTs, the sample was washed with $6 \mathrm{M} \mathrm{HCl}$. Subsequently, the sample was washed copiously with de-ionized water, filtered using G4 crucible and dried at $80^{\circ} \mathrm{C}$. This sample is referred to as non-oxidized MWNTs (Non-Ox-CNT) in the following text.

\section{Preparation of Pt/CNT electrocatalyst}

In a typical deposition, $100 \mathrm{mg}$ of MWNTs sample (Non-Ox-CNT or Ox-CNT) was ultrasonically dispersed in $10 \mathrm{ml}$ of ethylene glycol and transferred to a round bottom flask. Chloroplatinic acid containing $10 \mathrm{mg}$ of platinum was dissolved in $1.5 \mathrm{ml}$ of ethylene glycol and was added drop wise to the CNTs dispersion under continuous stirring at room temperature $\left(\mathrm{ca} .30^{\circ} \mathrm{C}\right)$. The $\mathrm{pH}$ of the resulting mixture was maintained above 12 by adding $2 \mathrm{M} \mathrm{NaOH}$ in ethylene glycol with constant mechanical stirring. Platinum-deposited carbon nanotubes sample was obtained by heating the mixture at $130^{\circ} \mathrm{C}$ for $4 \mathrm{~h}$ in an oil bath. The solid mass was filtered and washed copiously with deionized water and heated in a vacuum oven at $100^{\circ} \mathrm{C}$ for $6 \mathrm{~h}$.

\section{$\underline{\text { Preparation of membrane electrode assembly }}$}

Electrodes (anode and cathode) consist of a backing layer, a gas diffusion-layer and a reactive catalyst-layer. A teflonised (15\% PTFE) carbon paper of thickness 0.37 $\mathrm{mm}$ was used as the backing layer for both the electrodes. For gas-diffusion layer, the slurry was prepared by agitating Vulcan XC-72R carbon in cyclohexane for $30 \mathrm{~min}$ followed by the addition of $15 \%$ PTFE suspension under continuous ultrasonic agitation. The resulting slurry was spread onto a teflonised carbon paper and sintered in a furnace at $350^{\circ} \mathrm{C}$ for $30 \mathrm{~min}$. To prepare the active layer, required amount of catalyst $(\mathrm{Pt} / \mathrm{Non}-\mathrm{Ox}-$ CNTs or Pt/Ox-CNTs) was suspended in ethanol and the mixture was agitated ultrasonically. The required amount of Nafion solution, namely $7 \%$ on anode and $30 \%$ on cathode, was added to it under continuous agitation for $1 \mathrm{~h}$. The catalyst ink was coated on the gas-diffusion layer to prepare the electrodes. The anode and cathode were loaded with $0.11 \mathrm{mg} \mathrm{cm}^{-2}$ platinum (active area $=4 \mathrm{~cm}^{2}$ ). A thin layer of Nafion solution was applied onto the electrodes. MEAs were obtained by sandwiching Nafion-1135 
membrane between the two electrodes followed by compaction at $25 \mathrm{kN}\left(60 \mathrm{~kg} \mathrm{~cm}^{-2}\right)$ at $120^{\circ} \mathrm{C}$ for $3 \mathrm{~min}$.

\section{$\underline{\text { Physico-chemical characterization of MWNTs and Pt/CNTs }}$}

The characterization of MWNTs was carried out by recording powder x-ray diffraction patterns using Philips Pan Analytical X-ray Diffractometer between $20^{\circ}$ and $80^{\circ}$ in reflection geometry in steps of $2^{\circ} \mathrm{min}^{-1}$ employing $\mathrm{CuK}_{\alpha}$ radiation $(\lambda=1.5406 \AA)$. Surface-area measurements were carried out by $\mathrm{N}_{2}$-physisorption. Adsorption-desorption isotherms obtained at 77K using a Micromeritics ASAP 2020. Total surface area was determined using Brunauer-Emmett-Teller (BET) equation and pore-size distribution curves were obtained by Barrett-Jyoner-Halenda (BJH) method. XPS for Pt/CNT catalysts were obtained using ESCA Thermofisher Scientific, UK (Multilab Model 2000). The particle-size distribution and average platinum-particle-size for catalysts were obtained by bright-field micrographs recorded using FEI, Philips Technai F30 TEM.

\section{$\underline{\text { Polarization studies }}$}

Polarization studies on the MEAs were conducted using conventional fuel cell test fixture under the experimental conditions described elsewhere ${ }^{3}$. In brief MEAs were performance evaluated using fuel cell fixtures with parallel serpentine flow field machined on graphite plates (Schunk Kohlenstofftechnic). After equilibration, the cells were tested at $70^{\circ} \mathrm{C}$ with gaseous hydrogen at anode and gaseous oxygen at cathode at atmospheric pressure. The flow rates for both hydrogen and oxygen gases were kept at 1.5 slpm. Galvanostatic polarization data were obtained using Arbin Instruments.

\section{Electrochemical Durability Studies}

Cyclic voltammetry in cell mode: Cyclic voltammetric (CV) studies were carried out at $70^{\circ} \mathrm{C}$ to measure the electrochemical surface area employing a potentiostat (AutolabPGSTAT 30) in fuel cell mode. Cell anode is employed as reference cum counter electrode while cell cathode acts as the working electrode. Gaseous hydrogen was supplied to the anode and nitrogen was supplied to the cathode. CV was recorded after a run time of $2 \mathrm{~h}$. The electrode was cycled between 0 to $1 \mathrm{~V}$ to obtain a stable response. ESA of platinum catalyst was determined as below.

$$
\mathrm{ESA}=\mathrm{Q}_{\mathrm{H}} /\left[\text { Area of the electrode }\left(\mathrm{cm}^{2}\right) \times 210 \mu \mathrm{C} \mathrm{cm}^{-2} \times \mathrm{Pt} \text { loading }\left(\mathrm{mg} \mathrm{cm} \mathrm{cm}^{-2}\right)\right]
$$

where $Q_{H}$ represents the charge associated with hydrogen adsorption, $210 \mu \mathrm{C} \mathrm{cm}^{-2}$ is the charge required to oxidize a monolayer of hydrogen on smooth platinum surface.

Chronoamperometry and Cyclic voltammetry: Electrochemical oxidation experiments were conducted in a three-electrode electrochemical cell using a glassy carbon electrode with saturated calomel electrode (SCE) as a reference electrode and a platinum wire counter electrode. The working electrode was prepared using a thin-film technique. During electrochemical oxidation experiments, the working electrode was immersed in $1 \mathrm{M} \mathrm{H}_{2} \mathrm{SO}_{4}$ purged with nitrogen. A constant potential of $0.9 \mathrm{~V}$ was applied to the working electrode using a potentiostat and was held for $12 \mathrm{~h}$ to study the corrosion behavior of MWNTs. Cyclic voltammetry was conducted on nanotube electrodes in $1 \mathrm{M}$ 
aq. $\mathrm{H}_{2} \mathrm{SO}_{4}$ solution prior and after the electrochemical oxidation to observe the formation of surface oxides.

\section{$\underline{\text { Characterization }}$}

\section{Results and discussion}

MWNTs have been characterized by both XRD and BET surface-area measurements after surface-treatments so as to understand the structural changes induced during the oxidation process. XRD patterns for oxidized and non-oxidized carbon nanotubes samples are shown in Figure 1.

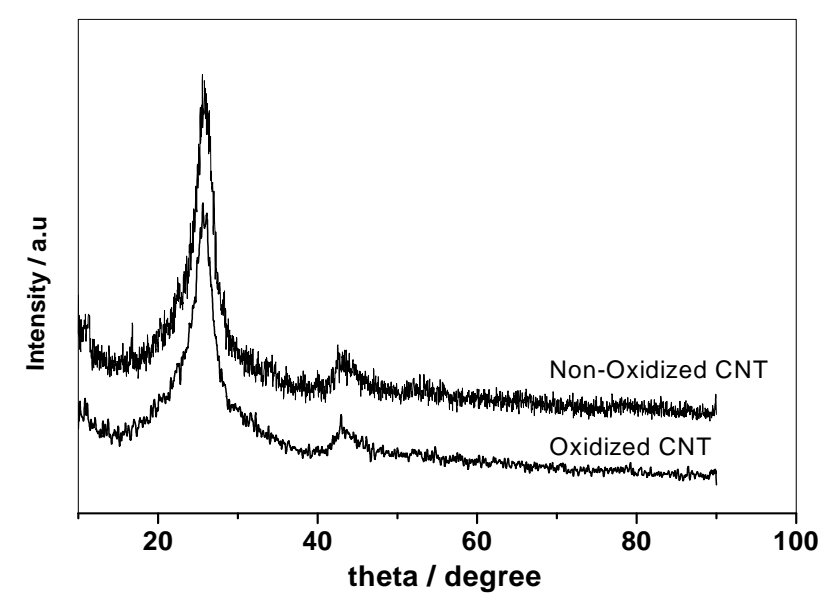

Figure 1. XRD patterns of Non-Oxidized and Oxidized MWNT samples.

XRD pattern of non-oxidized MWNTs exhibits a strong and sharp peak at $2 \theta=25.80^{\circ}$, which is characteristic of the (002) diffraction peak for an ideal graphite phase. The dspacing value corresponding to this diffraction peak is found at $3.38 \AA$, while XRD pattern of the oxidized nanotube showed a peak at $2 \theta=25.85^{\circ}$ corresponding to the $d$ spacing of about $3.41 \AA$. The d-spacing for non-oxidized nanotube is not only lower than the oxidized sample but also much closer to the d-spacing (3.354 $\AA$ ) for an ideal graphitic structure.

To understand the change in structural features, pore structures for surface-treated MWNTs are also characterized by $\mathrm{N}_{2}$-sorption method at $77 \mathrm{~K}$. The method is used to measure the specific surface area, pore-size distribution (PSD) and pore-volume of porous materials. Figure 2(a) shows the adsorption-desorption isotherms for MWNTs. 

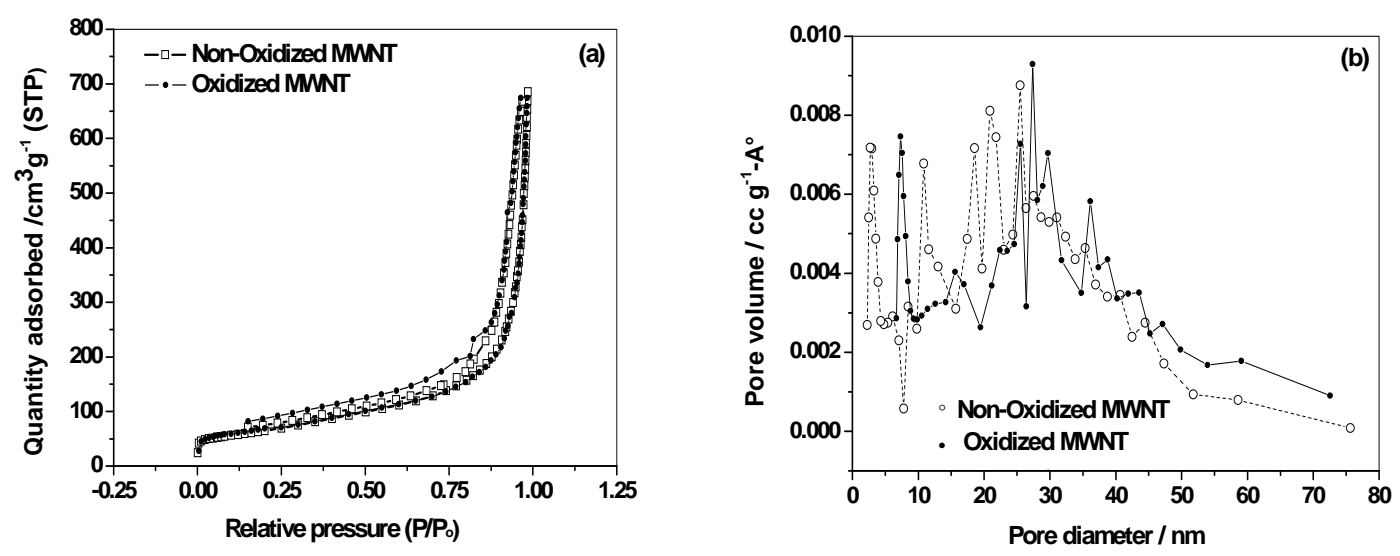

Figure 2. (a) $\mathrm{N}_{2}$ adsorption isotherms for Non-Ox-CNT and Ox-CNT samples, and (b) typical pore-size distribution in Non-Ox-CNT and Ox-CNT samples.

According to the IUPAC classification, adsorption-desorption isotherm of MWNTs follow type I/II and the hysteresis loop belongs to the type-H3. Although both the non-oxidized and oxidized MWNTs samples follow a similar trend in adsorptiondesorption, there is a difference in the behavior at relative pressures below 0.8. This indicates that on functionalizing MWNTs by nitric acid, the volume of small pores decreases while larger pores remain practically unaffected. BET surface area for the two samples, before and after oxidation, are found to be 228 and $251 \mathrm{~m}^{2} / \mathrm{g}$, respectively. Poresize distribution data shown in Figure 2(b) also supports the above observation. Increase in the surface area after nitric acid oxidation indicates structural order to be affected. In spite of an observed increase in surface area, mass activity is found to be less for $\mathrm{Pt} / \mathrm{Ox}-$ CNTs akin to results reported earlier ${ }^{4}$. Thus, mass activity does not depend on carbon surface area alone but is also greatly influenced by pore-size distribution within the carbon support. On functionalizing the MWNTs, pore-volume due to larger pores increases while pore volume due to pores $<20 \mathrm{~nm}$ decreases. Pores $<20 \mathrm{~nm}$ act as hydrophobic gas-diffusion-channels supplying reactants to the platinum sites and the contribution of these pores is noticeably high for non-oxidized MWNTs. Accordingly, higher mass activity of platinum supported on non-oxidized MWNTs is observed.

Figure 3 depicts Pt (4f) XPS for the Pt/Non-Ox-CNT with two sets of spin-orbit doublets. The doublet at $71.1 \mathrm{eV}$ and $74.4 \mathrm{eV}$ is characteristic of Pt (0) species while the doublet at $72.7 \mathrm{eV}$ and $75.9 \mathrm{eV}$ is assigned to $\mathrm{Pt}(+2)$ species with the $\mathrm{Pt}(0)$ species being predominant. Interestingly, the Pt (4f) XPS for Pt/Non-Ox-CNT (spectra not shown) is found to be similar to the Pt (4f) XPS for Pt/Ox-CNT suggesting little change in PtMWNTs interaction on oxidizing MWNTs support. 


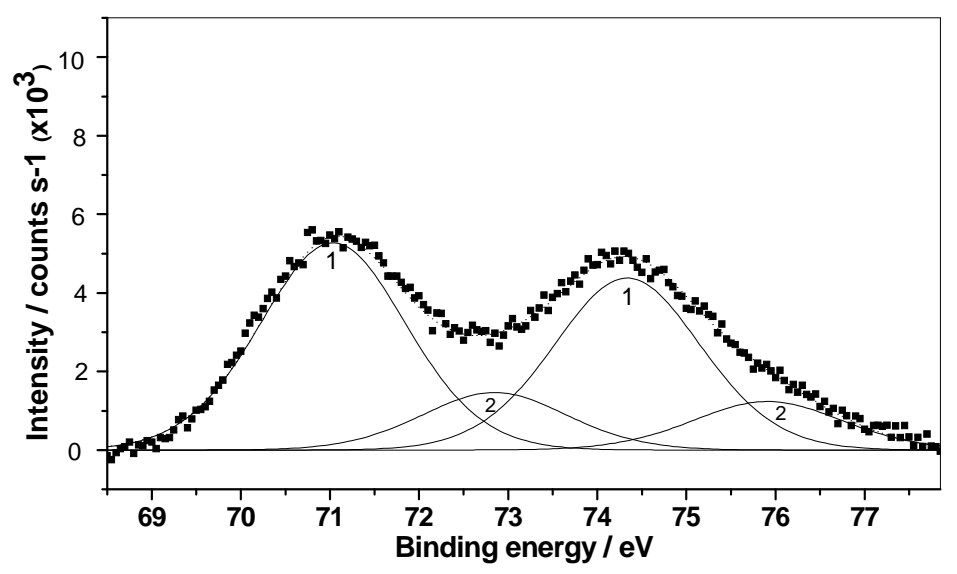

Figure 3. Pt (4f) XPS recorded on the platinum-supported non-oxidized CNTs.

TEM images for Pt/Non-Ox-CNTs and Pt/Ox-CNTs platinum deposition are presented in the Figure 4(a) and 4(b), respectively. Dispersion of platinum is almost similar on both supports. The average particle-size of Pt is $3.9 \pm 0.2 \mathrm{~nm}$ and $2.7 \pm 0.2 \mathrm{~nm}$ for Pt/Non-Ox-CNTs and Pt/Ox-CNTs, respectively.
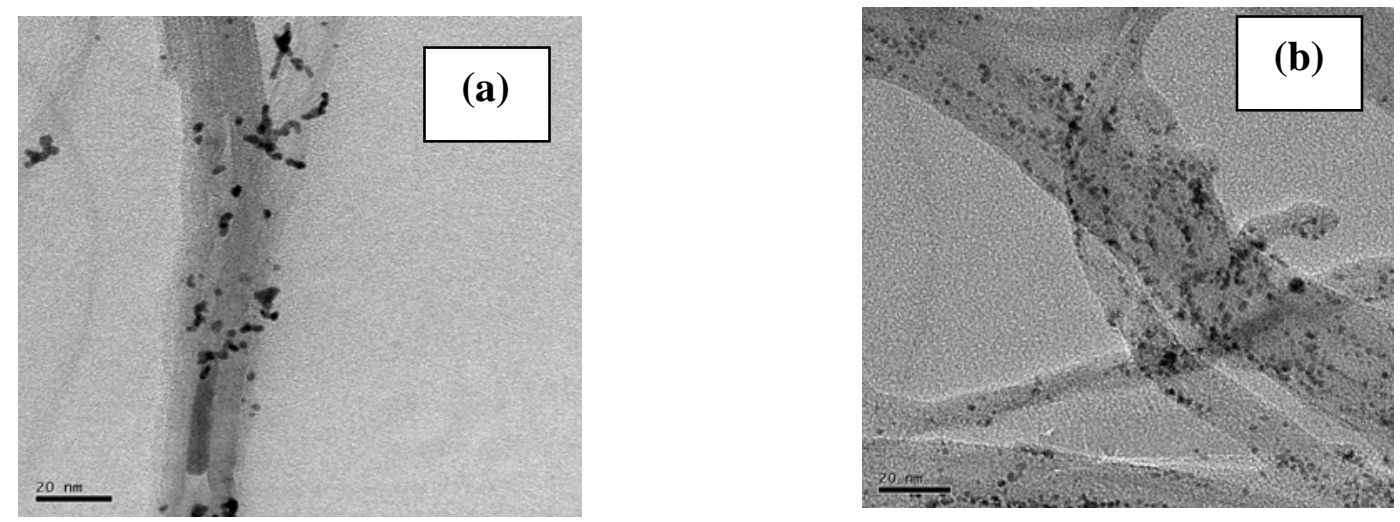

Figure 4. TEM micrographs for (a) Pt/Non-Ox-CNTs and (b) Pt /Ox-CNTs.

It will be shown later that relatively larger Pt particle supported on the non-oxidized MWNTs do not affect the catalytic activity.

\section{$\underline{\text { Electrochemical measurements }}$}

The potential cycles are recorded between 0 to $1 \mathrm{~V}$ at $50 \mathrm{mV} / \mathrm{s}$ with $\mathrm{MEAs}$ comprising of Pt/Non-Ox CNTs and Pt /Ox-CNTs. Figure 5 (a) and 5(b) show the representative CVs with increasing cycle number up to 500 cycles. ESA calculated from $\mathrm{CVs}$ is plotted as a function of number of cycles and data are presented in Figure 6. There is a $19 \%$ decrease in ESA after 500 cycles for Pt/Ox-CNTs while it is less than $10 \%$ in case of Pt/Non-Ox-CNTs. The observed data could be explained on the basis of corrosion resistance of carbon supports under electrochemical potential sweeping conditions. 

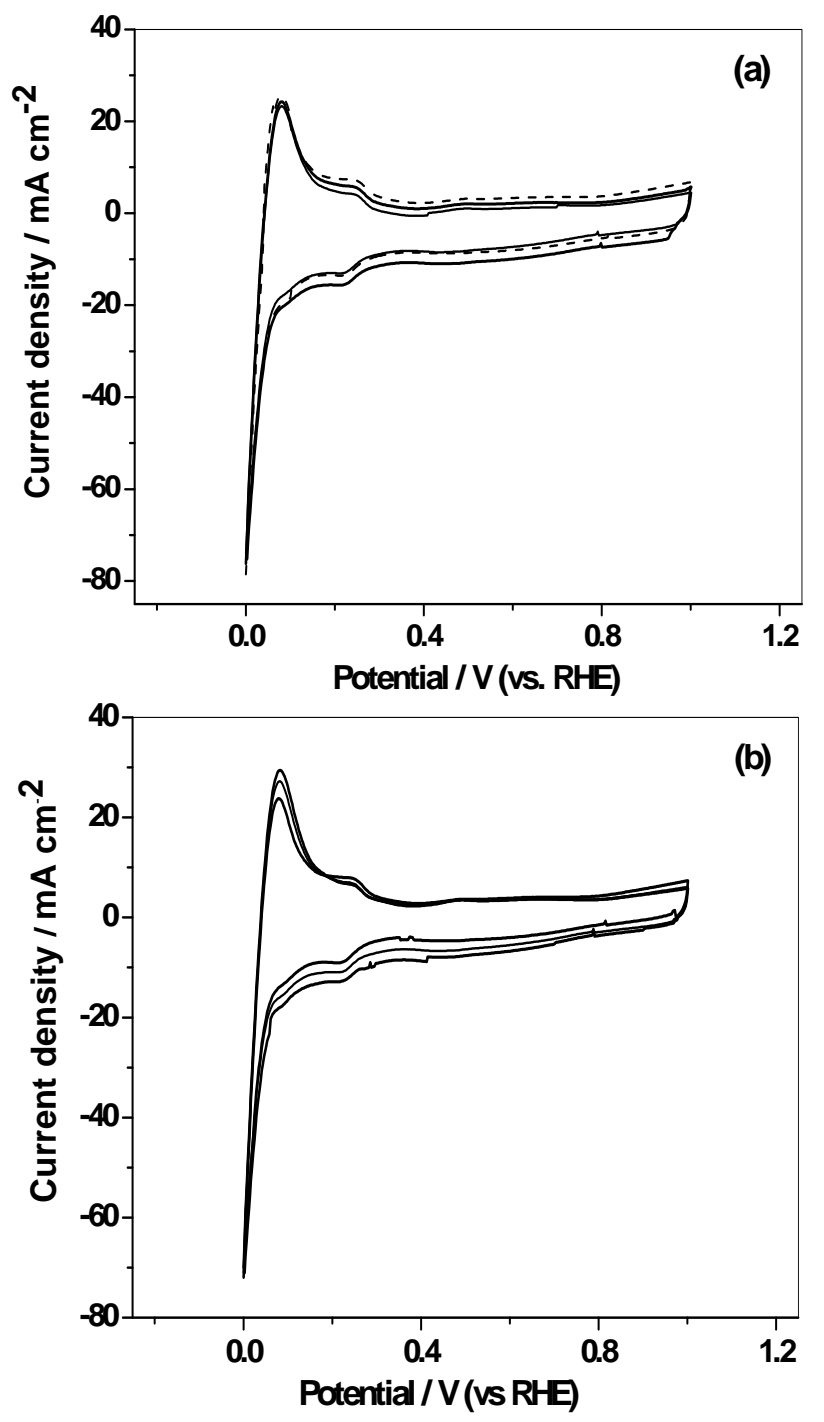

Figure 5. Cyclic voltammertic data for (a) Pt/Non-Ox-CNTs and (b) Pt/Ox-CNTs at a scan rate of $50 \mathrm{mV} \mathrm{s}^{-1}$ and the potential window between 0 to $1 \mathrm{~V}$ with $\mathrm{N}_{2}$ and $\mathrm{H}_{2}$ streams at cathode and anode, respectively.

During nitric acid treatment MWNTs are shortened into small tubes and additional defects are generated in the graphitic network. These defects affect the structural stability of the material by acting as potential sites during oxidation. According, loss in ESA associated with Pt/Ox-CNTs is higher. 


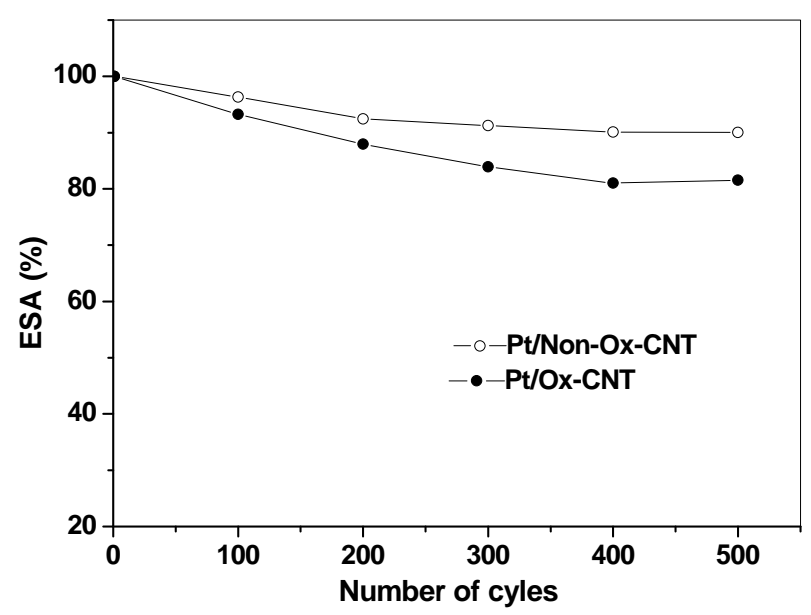

Figure 6. ESA of Pt/Non-Ox-CNTs and Pt/Ox-CNTs with varying number of potential cycles.

To further investigate the electrochemical corrosion behavior of non-oxidized and oxidized MWNTs, a study is performed with non-platinized and platinized electrodes of different nanotubes supports by holding the modified GC electrode at a potential of $0.9 \mathrm{~V}$ (vs. SCE) for $12 \mathrm{~h}$ in $1 \mathrm{M} \mathrm{H}_{2} \mathrm{SO}_{4}$. Under the potentiostatic condition, carbon is more prone to electrochemical oxidation. $\mathrm{CV}$ data are therefore recorded to follow carbon corrosion.

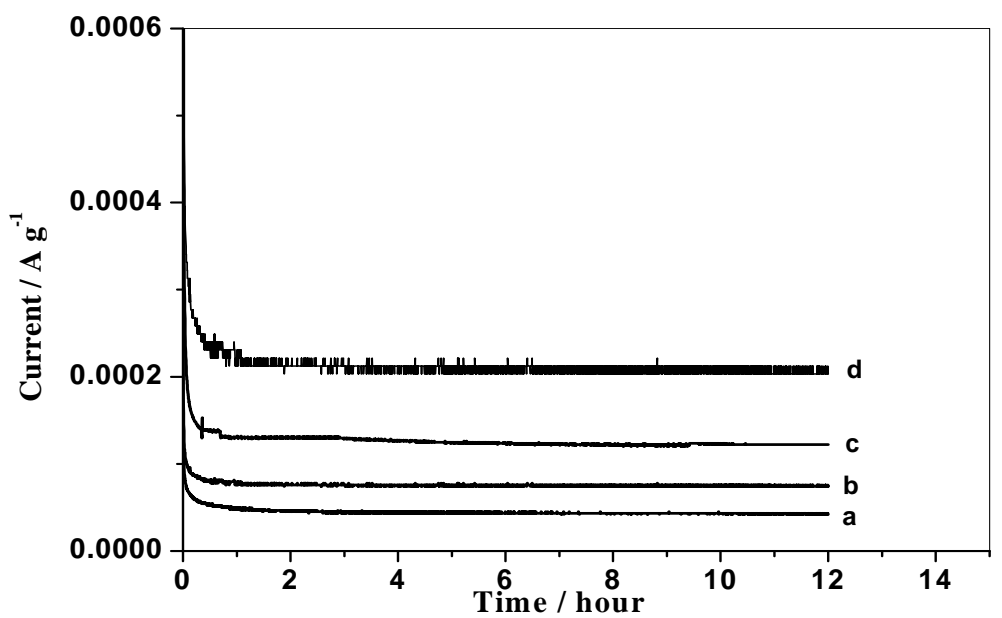

Figure 7. Chronoammperometric data for (a) Non-oxidized MWNTs, (b) Oxidized MWNTs, (c) Pt/Non-Ox-CNTs and (d) Pt/Ox-CNTs recorded at $0.9 \mathrm{~V}$ vs. SCE in $1 \mathrm{M}$ $\mathrm{H}_{2} \mathrm{SO}_{4}$ under nitrogen purged conditions.

From Figure 7, it is evident that with non-oxidized MWNTs support corrosion current (Figure 7(a)) is lower by $21 \%$ in relation to oxidized MWNTs (Figure 7 (b)). The electrochemical oxidation current for Pt-supported MWNTs is higher than that for nonplatinised MWNTs as shown in Figure 7(c) and (d). But the effect of increase in the corrosion current is more conspicuous in the case of oxidized MWNTs rather than that for non-oxidized MWNTs. In summary, when non-oxidized MWNTs are catalyzed with 
platinum, enhancement in corrosion current is only $26 \%$ while it is nearly $40 \%$ with oxidized MWNTs.
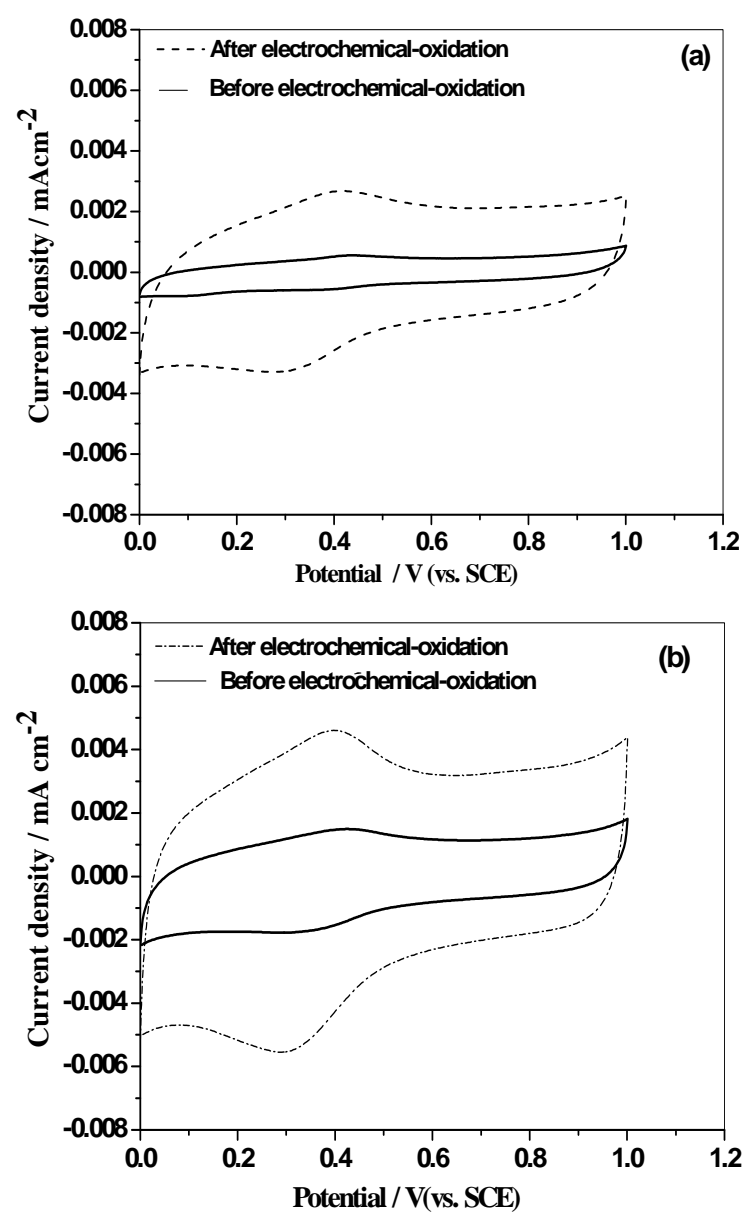

Figure 8. Cyclic voltammograms of MWNTs before and after electrochemical oxidation measurement (a) Non-oxidized MWNTs and (b) Oxidized MWNTs measured between 0 to $1 \mathrm{~V}$ at a scan rate of $50 \mathrm{mVs}^{-1}$.

Figure 8 shows CV data for non-oxidized and oxidized MWNTs. Before electrochemical oxidation, CVs of both MWNTs samples are flat while current is mainly due to double-layer charging. After electrochemical oxidation, redox peaks become prominent accompanied with an increase in the capacitive current for both the supports. It is obvious from the $\mathrm{CV}$ data that the amount of surface oxides generated due to oxidation is higher when MWNTs are oxidized chemically. A closer observation of CVs also reveals that anodic peak potential occurs at $0.39 \mathrm{~V}$ for oxidized MWNTs whereas it is shifted to $0.41 \mathrm{~V}$ for non-oxidized MWNTs subsequent to electrochemical oxidation. Positive shift associated with non-oxidized MWNTs also implies that it is difficult to oxidize the surface as it is more resistant to formation of surface oxides. The electrochemical characterization proves that non-oxidized MWNTs with ordered defectfree structure is more durable than oxidized MWNTs and suitable as an electrode material for PEFCs. 
Figure 9 shows polarisation data for $\mathrm{H}_{2}-\mathrm{O}_{2}$ PEFC comprising Pt/Non-Ox -CNTs and $\mathrm{Pt} / \mathrm{Ox}-\mathrm{CNT}$ s with their current densities expressed in terms of $\mathrm{mA} \mathrm{mg}^{-1}$. Mass activity of $\mathrm{Pt} / \mathrm{Non}-\mathrm{Ox}-\mathrm{CNT}$ s is superior in relation to Pt/Ox-CNTs. IR-corrected values at $0.9 \mathrm{~V}$ are $110 \mathrm{~mA} \mathrm{mg}^{-1}$ and $75 \mathrm{~mA} \mathrm{mg}^{-1}$, respectively. High electrical conductivity of non-oxidized MWNTs is beneficial for providing electron pathways and enhancing the triple- phase boundaries.

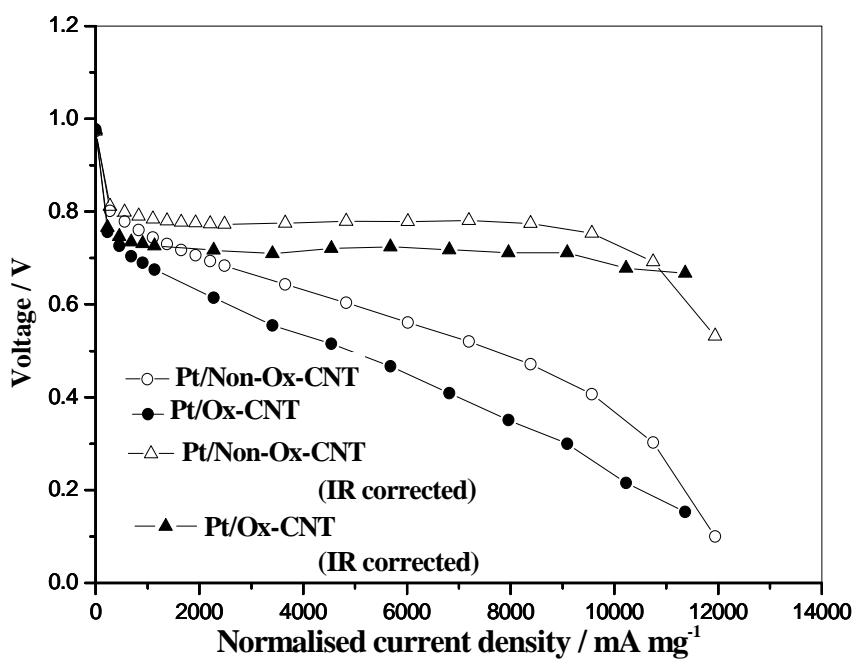

Figure 9. Polarization data obtained at $70^{\circ} \mathrm{C}$ for PEFCs with $\mathrm{Pt} / \mathrm{Non}-\mathrm{Ox}-\mathrm{CNTs}$ and $\mathrm{Pt} / \mathrm{Ox}-$ CNTs having $0.11 \mathrm{mg} \mathrm{Pt}^{-2}$ on each side before and after IR-correction.

The experimental polarization data are analyzed using the equation,

$$
\mathrm{V}=\mathrm{V}_{0}-\mathrm{b} \log \mathrm{I}-\mathrm{RI}
$$

where $\mathrm{V}$ and I are the experimentally measured cell voltage and current, and $\mathrm{b}$ and $\mathrm{R}$ are the Tafel slope and total resistance. The experimental data are fitted to the above equation by a non-linear-least-square method to calculate the kinetic parameters of the different electrocatalysts from regression analysis (Table I).

Table I. Electrochemical kinetic parameters for PEFCs with platinum supported on different MWNTs supports.

\begin{tabular}{|c|c|c|c|c|}
\hline Catalyst & $\mathrm{E}_{\mathrm{o}}(\mathrm{V})$ & $\begin{array}{c}\mathrm{i}_{0.9 \mathrm{~V}} \\
\left(\mathrm{~mA} \mathrm{mg}^{-1}\right)\end{array}$ & $\begin{array}{c}\text { Tafel slope } \\
(\mathrm{V} / \mathrm{decade})\end{array}$ & $\begin{array}{c}\mathrm{R} \\
\left(\Omega \mathrm{cm}^{2}\right)\end{array}$ \\
\hline $\begin{array}{c}\text { Pt/Non-Ox } \\
\text { CNTs }\end{array}$ & 0.97 & 110 & 0.049 & 0.32 \\
\hline Pt/Ox-CNTs & 0.97 & 75 & 0.053 & 0.41 \\
\hline
\end{tabular}

It is clear that higher performance is obtained with Pt/Non-Ox-CNTs primarily due to low resistance. In spite of an improved platinum catalytic activity and lower ohmic drop, at higher current densities non-oxidized nanotubes supported platinum catalyst presents a 
loss in the cell voltage due to mass polarization loss on account of lower population of meso and macrospores. Pt utilization $\left(\mathrm{U}_{\mathrm{Pt}}\right)$ is a measure of number of $\mathrm{Pt}$ atoms actively participating in the reaction.

$$
\mathrm{U}_{\mathrm{Pt}}=\mathrm{ESA} / \mathrm{S}_{\mathrm{Pt}}
$$

where ESA is electrochemically active area determined from hydrogen adsorption/desorption charge $\mathrm{Q}_{\mathrm{H}}$ in $\mathrm{CV}$ and $\mathrm{S}_{\mathrm{Pt}}$ is the total surface area calculated from Pt particle size. $\mathrm{U}_{\mathrm{Pt}}$ for Pt/Non-Ox-CNTs and $\mathrm{Pt} / \mathrm{Ox}-\mathrm{CNT}$ s are found to be $55 \pm 5 \%$ and $39 \pm 5 \%$, respectively. Difference in $\mathrm{U}_{\mathrm{Pt}}$ substantiates the optimal electrode configuration provided by the non-oxidized structure that helps increasing the three-phase contacts mandatory for the electrochemical reaction in fuel cell.

A peak power density of $450 \mathrm{~mW} \mathrm{~cm}^{-2}$ at $930 \mathrm{~mA} \mathrm{~cm}^{-2}$ is obtained for a loading of $0.11 \mathrm{mg}_{\mathrm{Pt}} \mathrm{cm}^{-2}$ using Non-Ox-CNTs as support which is superior to $270 \mathrm{~mW} \mathrm{~cm}^{-2}$ at 930 $\mathrm{mA} \mathrm{cm}{ }^{-2}$ obtained using Ox-CNTs. These values are far higher than that reported for OxCNTs namely maximum power density of $80 \mathrm{mWcm}^{-2}$ with a loading of $0.2 \mathrm{mg}_{\mathrm{Pt}} \mathrm{cm}^{-2}$ while $480 \mathrm{mWcm}^{-2}$ for an MEA comprising $0.25 \mathrm{mg}_{\mathrm{Pt}} \mathrm{cm}^{-2}$ (anode) and $0.5 \mathrm{mg}_{\mathrm{Pt}} \mathrm{cm}^{-2}$ (cathode) loadings for CNTs-supported catalyst ${ }^{5}$.

The results suggest that non-oxidized MWNTs could outperform the oxidized MWNTs in terms of both platinum mass activity and the corrosion-resistance, and accordingly are more appropriate catalyst-support material for PEFCs. If is suggested that effective pre-treatment method without affecting MWNTs structure is essential for furthering the performance of PEFCs with minimal platinum loading.

\section{Acknowledgements}

Financial support from CSIR, New Delhi is gratefully acknowledged.

\section{References}

1. J. Larminie and A. Dicks, Fuel cell Systems Explained, Wiley, New York (2000).

2. T. Matumoto, K. Arai, T. Yamazaki, M. Kijima, H. Shimizu, Y. Takasawa and J. Nakamura, Chem commun., 840 (2004).

3. G. Selvarani, A. K. Sahu, N. A. Choudhury, P. Sridhar, S. Pitchumani and A. K. Shukla, Electochim.Acta., 524871 (2007).

4. J. Kaiser, P.A. Simonov, V. I. Zaikovskii, C. Hartnig, L. Jorissen, E.R. Savinova, J.Appl Electrochem.371429 (2007).

5. N. Rajalakshmi, H. Ryu, M. M. Shaijumon S. Ramaprabhu, J.Power Sources, 140 $240(2005)$. 